\title{
Synthesis and catalytic property of urania-palladium-graphene nanohybrids
}

\author{
Li Ding, Zeyao Zhang and Yan $\mathrm{Li}^{*}$
}

\begin{abstract}
Urania-palladium-graphene nanohybrids were synthesized via a solvothermal process in ethylene glycol. With the solvothermal treatment, the Pd nanocrystals surrounded by well-crystallized urania supported on graphene oxide was obtained. This ternary hybrid showed considerably higher catalytic activity than palladium-graphene hybrids toward the reduction of 4-nitrophenol by $\mathrm{NaBH}_{4}$. Besides the smaller sizes of palladium nanoparticles in the ternary hybrids, in which the aggregation of Pd nanoparticles was prevented by urania, the charge transfer between the nano-structured Pd and urania may also contribute to the enhancement of catalytic activity by offering more active sites for adsorption and reaction.
\end{abstract}

Keywords: uranium oxides, palladium, catalytic performance

\section{INTRODUCTION}

Uranium is one of the natural radioactive elements. Many current applications of uranium are based on its unique nuclear properties. The natural isotopes of uranium consist of ${ }^{238} \mathrm{U}(99.275 \%),{ }^{235} \mathrm{U}(0.720 \%)$, and a very small amount of ${ }^{234} \mathrm{U}(0.0050 \%)$ [1]. In the nuclear reactor, the fuel is normally enriched of ${ }^{235} \mathrm{U}$. Therefore, a large amount of ${ }^{238} \mathrm{U}$, which has an ultralong half-life period of $\sim 4.5$ billion years and hence is normally safe to be exploited conventionally, is abandoned from nuclear industry $[1,2]$. Therefore, developing applications of the residual ${ }^{238} \mathrm{U}$ is of great importance.

Uranium is rich of $5 f$ electrons which render it splendid chemical properties such as variable valence states and multiple oxide phases. The principal thermodynamically stable binary oxides are $\mathrm{UO}_{2}, \mathrm{U}_{4} \mathrm{O}_{9}, \mathrm{U}_{3} \mathrm{O}_{8}$ and $\mathrm{UO}_{3}$. Many other metastable oxides also exist $[3,4]$. Uranium oxide with flexible oxidation states, has wide applications in catalysis [5-7]. For instance, mix-valence uranium oxide $\mathrm{U}_{3} \mathrm{O}_{8}$ is efficient for destroying a range of hydrocarbon and chlorine-containing pollutants under mild condition $[8,9]$. Uranium dioxide (urania) shows a hydrogen evolution electrocatalytic activity when combined with graphene [10]. Nevertheless, uranium oxides were seldom tested as the promoter in catalytic reaction, comparing to the conventional metal oxides $[11,12]$. However, the unique redox property may endow uranium oxides special advantage in serving as a catalyst promoter.

Palladium nanoparticles have very important applications in catalysis, for instance, as catalyst in Suzuki-Coupling reaction [13-16], low temperature CO oxidation, 4-nitrophenol reduction and so on [17-22]. In particular, the reduction of 4-nitrophenol to 4-aminophenol over Pd catalysts in the presence of $\mathrm{NaBH}_{4}$ is of interest, because the product is a key intermediate compound for pharmaceuticals, agrochemicals, dyes, and pigments [23]. The combination of $\mathrm{Pd}$ and uranium oxides may bring about enhanced catalytic properties.

In order to maintain the nano-scaled morphology and structure of both Pd and uranium oxide, which are normally important to ensure the higher catalytic activity, the third component may need to be introduced as a supportive and/or dispersive agent. Graphene oxide (GO) is an ideal catalyst support due to its extraordinarily high specific surface area and numerous hydrophilic functional groups on its surface, which can facilitate the nucleation of nanocrystals [24-27].

Herein, we synthesized the ternary nanohybrids of palladium and urania supported on GO (Scheme 1). The nanohybrids show remarkably improved catalytic performance. A possible synergetic mechanism between urania

Beijing National Laboratory for Molecular Sciences, Key Laboratory for the Physics and Chemistry of Nanodevices, State Key Laboratory of Rare Earth Materials, Chemistry and Applications College of Chemistry and Molecular Engineering, Peking University, Beijing 100871, China

* Corresponding author (email: yanli@pku.edu.cn) 


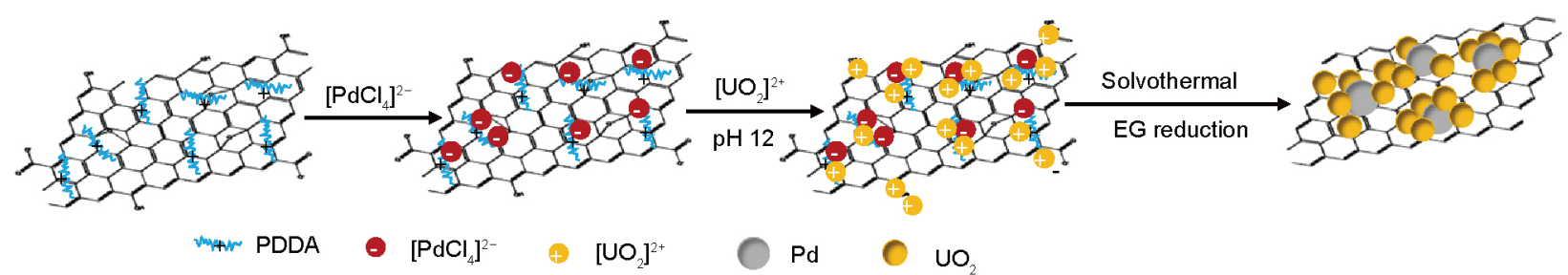

Scheme 1 Schematic illustration of the compositional and morphological evolution process of urania-palladium-graphene nanohybrids by solvothermal treatment.

and Pd was proposed.

\section{EXPERIMENTAL SECTION}

\section{Materials}

Graphite flakes (Sigma-Aldrich, cat \#332461), $\mathrm{KMnO}_{4}$ (guaranteed reagent (GR), Sinopharm Chemical Reagent), ethylene glycol (EG) (analytical reagent (AR), Sinopharm Chemical Reagent), $\mathrm{H}_{2} \mathrm{SO}_{4}$ (AR, Xilong Chemical), $\mathrm{HNO}_{3}$ (AR, Xilong Chemical), $\mathrm{H}_{3} \mathrm{PO}_{4}$ (GR, Beijing TongGuang Fine Chemical), $\mathrm{U}_{3} \mathrm{O}_{8}$ (AR, China National Nuclear), 20 wt.\% aqueous solution of poly(diallyldimethylammonium chloride) (PDDA) (Sigma-Aldrich), $\mathrm{KOH}$ (GR, Xilong Chemical), and $\mathrm{PdCl}_{2}$ (AR, Beijing TongGuang Fine Chemical) were used as received.

\section{Preparation of $\mathrm{Pd} / \mathrm{UO}_{2} / \mathrm{GO}$ hybrids}

Typically, $20 \mathrm{~mL}$ of PDDA-modified GO $\left(1 \mathrm{mg} \mathrm{mL} \mathrm{m}^{-1}\right)$ $[28,29]$ was dispersed in $80 \mathrm{~mL}$ of $\mathrm{EG}$ and sonicated for 5 min. Then $4 \mathrm{~mL} \mathrm{~K}_{2} \mathrm{PdCl}_{4}\left(0.1 \mathrm{~mol} \mathrm{~L}{ }^{-1}\right)$ was added. After the mixture was stirred overnight, its $\mathrm{pH}$ was adjusted to 12 with $1 \mathrm{~mol} \mathrm{~L}{ }^{-1} \mathrm{KOH}$. Immediately, $2 \mathrm{~mL}$ of $\mathrm{UO}_{2}{ }^{2+}(0.2 \mathrm{~mol}$ $\mathrm{L}^{-1}$ ) was added. The mixture was held at $140^{\circ} \mathrm{C}$ for $4 \mathrm{~h}$ under $\mathrm{N}_{2}$ atmosphere and then transferred into a Teflon-lined stainless steel autoclave to carry out a solvothermal reaction at $200^{\circ} \mathrm{C}$ for 4,12 , and $24 \mathrm{~h}$, respectively. The product was collected by centrifugation, washed with water, frozen by liquid nitrogen and lyophilized overnight.

\section{Preparation of Pd/GO hybrid}

All steps were the same as the preparation of $\mathrm{Pd} / \mathrm{UO}_{2} / \mathrm{GO}$ composite except for adding $\mathrm{UO}_{2}{ }^{2+}$.

\section{Characterization}

X-ray diffraction (XRD) measurements were performed on a Rigaku Dmax-2400 diffractometer using $\mathrm{Cu}$ Ka radiation $(\lambda=1.5406 \AA$ ) with an accelerating voltage of $40 \mathrm{kV}$ and current of $100 \mathrm{~mA}$ or a Panalytical X'Pert 3 Powder diffractometer using $\mathrm{Cu} \mathrm{Ka}$ radiation $(\lambda=1.5406 \AA)$ with an accelerating voltage of $40 \mathrm{kV}$ and a current of $40 \mathrm{~mA}$. The transmission electron microscopy (TEM) study was performed on a FEI Tecnai F20 electron microscope. X-ray photoelectron spectroscopy (XPS) was measured on an AXIS Ultra X-ray photoelectron spectroscope with Al-Ka radiation $(h v=1486.71 \mathrm{eV})$. X-ray source was operated at $225 \mathrm{~W}$ with $15 \mathrm{kV}$ acceleration voltage. The $\mathrm{C} 1 \mathrm{~s}$ line at $284.8 \mathrm{eV}$ was used to calibrate the binding energies. The UV-vis spectra were performed on a PerkinElmer Lambda 750. Inductively coupled plasma-atomic emission spectroscopy (ICP-AES) analysis was conducted on a Profile Spec ICP-AES spectrometer (Leeman, USA). The X-ray absorption fine structure (XAFS) in X-ray absorption spectra of Pd K-edge $\left(E_{0}=24,350 \mathrm{eV}\right)$ for Pd nanoparticles and $\mathrm{L}_{3}$-edge $\left(E_{0}=17,166 \mathrm{eV}\right)$ for uranium were collected at BL14W1 beamline of Shanghai Synchrotron Radiation Facility (SSRF). The energy was calibrated according to the absorption edge of pure $\mathrm{Pd}$ foil and $\mathrm{Zr}$ foil at K-edge $(17,998 \mathrm{eV})$.

\section{Catalytic reduction of 4-nitrophenol}

4-Nitrophenol $\left(25 \mu \mathrm{L}, 10 \mathrm{mmol} \mathrm{L}^{-1}\right)$ was dissolved in 2.425 $\mathrm{mL}$ water in a cuvette and bubbled with $\mathrm{N}_{2}$ for $60 \mathrm{~s}$ to remove the oxygen. Then $\mathrm{NaBH}_{4}$ aqueous solution $(500 \mu \mathrm{L}$, $\left.0.1 \mathrm{~mol} \mathrm{~L}^{-1}\right)$ was added. After the solution showed yellow color, $50 \mu \mathrm{L}\left(0.2 \mathrm{mg} \mathrm{mL}^{-1}\right)$ catalyst solution was added to ignite the reaction. The reaction progress was monitored by measuring the UV-vis absorption spectra of the reaction solutions.

\section{RESULTS AND DISCUSSION}

\section{Characterization of $\mathrm{Pd} / \mathrm{UO}_{2} / \mathrm{GO}$ nanohybrids}

As shown in Fig. 1a, c and e, there are nanoscaled materials loaded on GO. The high-resolution TEM (HRTEM) image in Fig. 1b shows fringes with an inter-distance of $0.22 \mathrm{~nm}$, which is in accordance to (111) plane of Pd. This indicates that Pd nanocrystals were formed after the solvothermal treatment of $4 \mathrm{~h}$. The typical particle size is around $\sim 6 \mathrm{~nm}$. In the sample of $12 \mathrm{~h}$ solvothermal treatment, weak fringes with the inter-distance of $0.27 \mathrm{~nm}$ were observed (Fig. 1d), which is assigned to the (200) plane of $\mathrm{UO}_{2}$. This indicates 


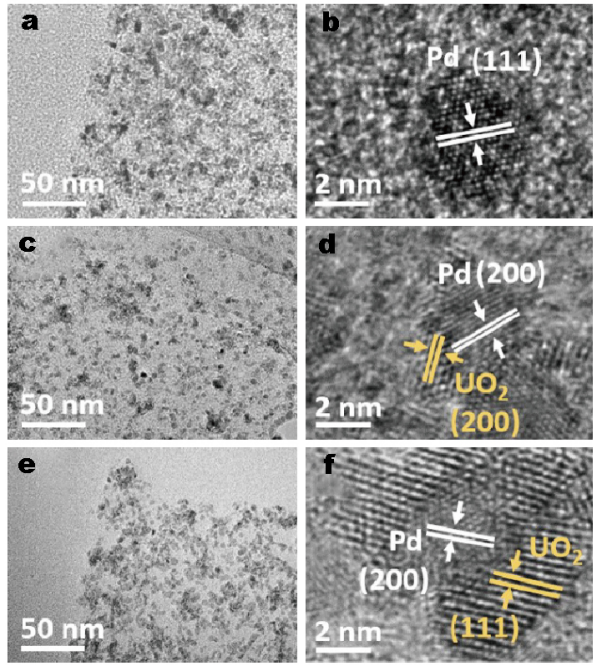

Figure 1 TEM and HRTEM images of $\mathrm{Pd} / \mathrm{UO}_{2} / \mathrm{GO}$ hybrids with the solvothermal time of $4 \mathrm{~h}(\mathrm{a}, \mathrm{b}), 12 \mathrm{~h}(\mathrm{c}, \mathrm{d})$, and $24 \mathrm{~h}(\mathrm{e}, \mathrm{f})$.

that the crystallized $\mathrm{UO}_{2}$ appeared. In the HRTEM image of the sample treated for $24 \mathrm{~h}$, very clear fringes with the space of $0.32 \mathrm{~nm}$ corresponding to (111) plane of $\mathrm{UO}_{2}$ were observed. It is obviously seen that the Pd nanoparticle was surrounded by $\mathrm{UO}_{2}$.

Fig. 2a shows the XRD patterns of the samples prepared at different conditions. All peaks are broadened due to the small grain size, which is consistent with the TEM images in Fig. 1. All the samples show characteristic peaks of Pd at $2 \theta=40.12^{\circ}, 46.66^{\circ}$, and $68.12^{\circ}$, which are indexed to (111), (200), and (220) plane, respectively. In the sample with 24 $\mathrm{h}$ solvothermal process, the peaks of crystal $\mathrm{UO}_{2}$ are clearly observed at $2 \theta=28.28^{\circ}, 32.74^{\circ}$, and $55.75^{\circ}$, which are indexed to (111), (200), and (311) plane, respectively. The very broad peak at $27-28^{\circ}$ appears in the samples with 4 and $12 \mathrm{~h}$ solvothermal treatment may be attributed to uranium oxide with poor crystallinity, which is in consistence with

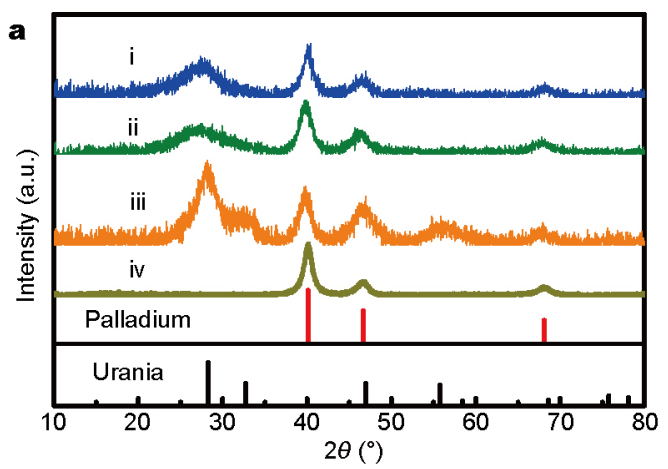

the HRTEM results. The XPS spectrum (Fig. 2b) shows that the sample contains $\mathrm{Pd}, \mathrm{U}, \mathrm{O}$, and $\mathrm{C}$ elements. The two peaks at 336 and $341 \mathrm{eV}$ can be respectively assigned to the binding energy of $P d 3 d_{5 / 2}$ and $3 d_{3 / 2}$, while the peaks at 382 and $393 \mathrm{eV}$ are assigned to $\mathrm{U} 4 \mathrm{f}_{7 / 2}$ and $\mathrm{U} 4 \mathrm{f}_{5 / 2}$.

From the above discussion, the ternary nanohybrids were prepared with Pd nanoparticles attached to nano-structured $\mathrm{UO}_{2}$. We estimated the grain size of Pd nanoparticles from the XRD results according to the Debye-Scherrer equation [30] (Table 1). The results are in good agreement with what we observed in TEM measurements. When comparing the samples with relative long solvothermal treatment, it is obvious that those with $\mathrm{UO}_{2}$ possess smaller Pd nanoparticles $(<5 \mathrm{~nm} v s .>20 \mathrm{~nm}$ ) because the presence of $\mathrm{UO}_{2}$ may help to prevent the Pd particles from aggregation.

\section{Catalytic activities for 4-nitrophenol reduction}

The ternary nanohybrids were used as catalysts for the reduction of 4-nitrophenol with an excess of $\mathrm{NaBH}_{4}$ as reducing agent. During the reaction, the absorption of 4-nitrophenol at $400 \mathrm{~nm}$ showed significant decrease, accompanied with a successive increase of absorption of 4 -aminophenol at $300 \mathrm{~nm}$ (Fig. 3a), which confirmed the catalytic activity of the ternary nanohybrids. Since the concentration of $\mathrm{NaBH}_{4}$ was largely exceeded the concentration of 4-nitrophenol in our experiments, the catalytic reduction can be treated as first-order kinetics regarding to the 4-nitrophenol concentration as reported [31-32]. This is confirmed by the linear relationship between $\ln \left(A / A_{0}\right)$ and the reaction time $t$ in Fig. $3 b$. The apparent rate constants $\left(\kappa_{\text {app }}\right)$ were calculated to be $6.1 \times 10^{-3} \mathrm{~s}^{-1}$ for the $\mathrm{Pd} / \mathrm{UO}_{2} / \mathrm{GO}$ and $3.1 \times 10^{-3} \mathrm{~s}^{-1}$ for the Pd/GO. As for the $\mathrm{UO}_{2} / \mathrm{GO}$ hybrid, nearly no reduction of 4-nitrophenol is observed, indicating that $\mathrm{UO}_{2}$ alone cannot catalyze the reduction reaction.

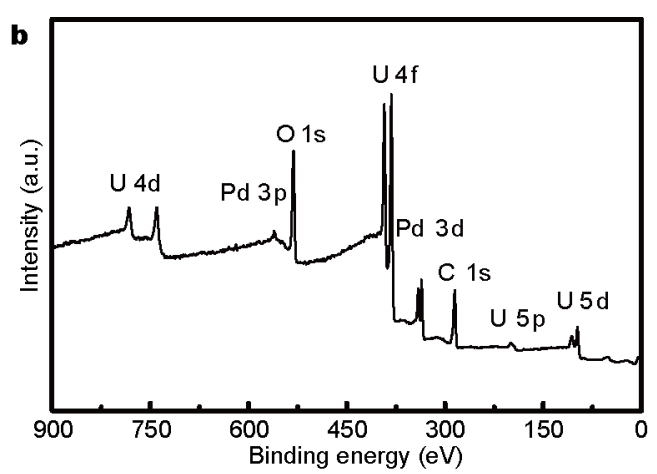

Figure 2 (a) XRD patterns of $\mathrm{Pd} / \mathrm{UO}_{2} / \mathrm{GO}$ hybrids with different solvothermal times (i, 4 h; ii, 12 h; iii, 24 h) and Pd/GO hybrid (iv) as comparison. (b) Typical XPS spectrum of the $\mathrm{Pd} / \mathrm{UO}_{2} / \mathrm{GO}$ hybrids with $24 \mathrm{~h}$ solvothermal treatment. 
Table 1 Crystallite size of $\mathrm{Pd}$ in $\mathrm{Pd} / \mathrm{GO}$ and $\mathrm{Pd} / \mathrm{UO}_{2} / \mathrm{GO}$ hybrids obtained at solvothermal time of 4 (S4), 12 (S12), and 24 (S24) h

\begin{tabular}{ccccc}
\hline Crystallite $(\mathrm{nm})$ & $(111)$ & $(200)$ & $(220)$ & Average \\
\hline $\mathrm{Pd} / \mathrm{GO}-\mathrm{S} 4$ & 6.9 & 6.1 & 6.1 & 6.4 \\
$\mathrm{Pd} / \mathrm{GO}-\mathrm{S} 12$ & 28 & 19.1 & 18.9 & 22.0 \\
$\mathrm{Pd} / \mathrm{GO}-\mathrm{S} 24$ & 25.1 & 16.5 & 18.7 & 20.1 \\
$\mathrm{Pd} / \mathrm{UO}_{2} / \mathrm{GO}-\mathrm{S} 4$ & 5.9 & 5.3 & 8.3 & 6.5 \\
$\mathrm{Pd} / \mathrm{UO}_{2} / \mathrm{GO}-\mathrm{S} 12$ & 5.0 & 4.4 & 5.1 & 4.8 \\
$\mathrm{Pd} / \mathrm{UO}_{2} / \mathrm{GO}-\mathrm{S} 24$ & 5.0 & 3.7 & 5.1 & 4.6 \\
\hline
\end{tabular}

To evaluate the performance of catalysts more precisely, we then calculated the rate constants of each catalyst based on the Pd quantity. The rate constants of $\mathrm{Pd} / \mathrm{UO}_{2} / \mathrm{GO}$ and $\mathrm{Pd} / \mathrm{GO}$ hybrids with different solvothermal treatment times were compared in Fig. 3c. We find that the ternary nanohybrids always show higher activity than Pd/GO. Particle size is often a key factor affecting the activity of the catalysts because smaller particles present larger surface area and more active sites [33-37]. The smaller size of Pd nanoparticles in the ternary hybrids as shown in Table 1, contributes to higher catalytic activity. This is also valid for the comparison in the catalytic performance of the Pd/GO with different solvothermal treatment times. However, the size effect cannot explain the difference in activity of the two samples with 4h's solvothermal treatment. Both samples show similar size of Pd nanoparticles, but the sample with $\mathrm{UO}_{2}$ exhibits higher catalytic activity. This indicates that $\mathrm{UO}_{2}$ should act more than just as a catalyst support. HRTEM and XRD characterizations shown in Figs 1 and $2 \mathrm{a}$ already reveal that longer solvothermal treatment benefits the formation of well crystallized $\mathrm{UO}_{2}$. From Fig. $3 c$ we also found that the catalytic activity of the $\mathrm{Pd} / \mathrm{UO}_{2} / \mathrm{GO}$ increases when prolonged the solvothermal time. This result gives further evidence indicating $\mathrm{UO}_{2}$ acting as a promoter for Pd rather than only a support. In addition, we optimized the ratio between $\mathrm{Pt}$ and $\mathrm{UO}_{2}$. As shown in Fig. 3d, the most suitable molar ratio is around $1: 1$. Higher content of $\mathrm{UO}_{2}$ leads to a decline of activity, which is possibly caused by covering the active sites of $\mathrm{Pd}$ catalysts.

To analyze the mechanism of the superior activity of the $\mathrm{Pd} / \mathrm{UO}_{2} / \mathrm{GO}$ hybrids and the role of $\mathrm{UO}_{2}$, we did XPS measurements (Fig. 4). Palladium does not show obvious valence change in different samples. But it is observed that uranium on the surface of $\mathrm{Pd} / \mathrm{UO}_{2} / \mathrm{GO}$ presents mix valence of +4 and +6 and the content of $U(+6)$ component became lower when the solvothermal time was prolonged.
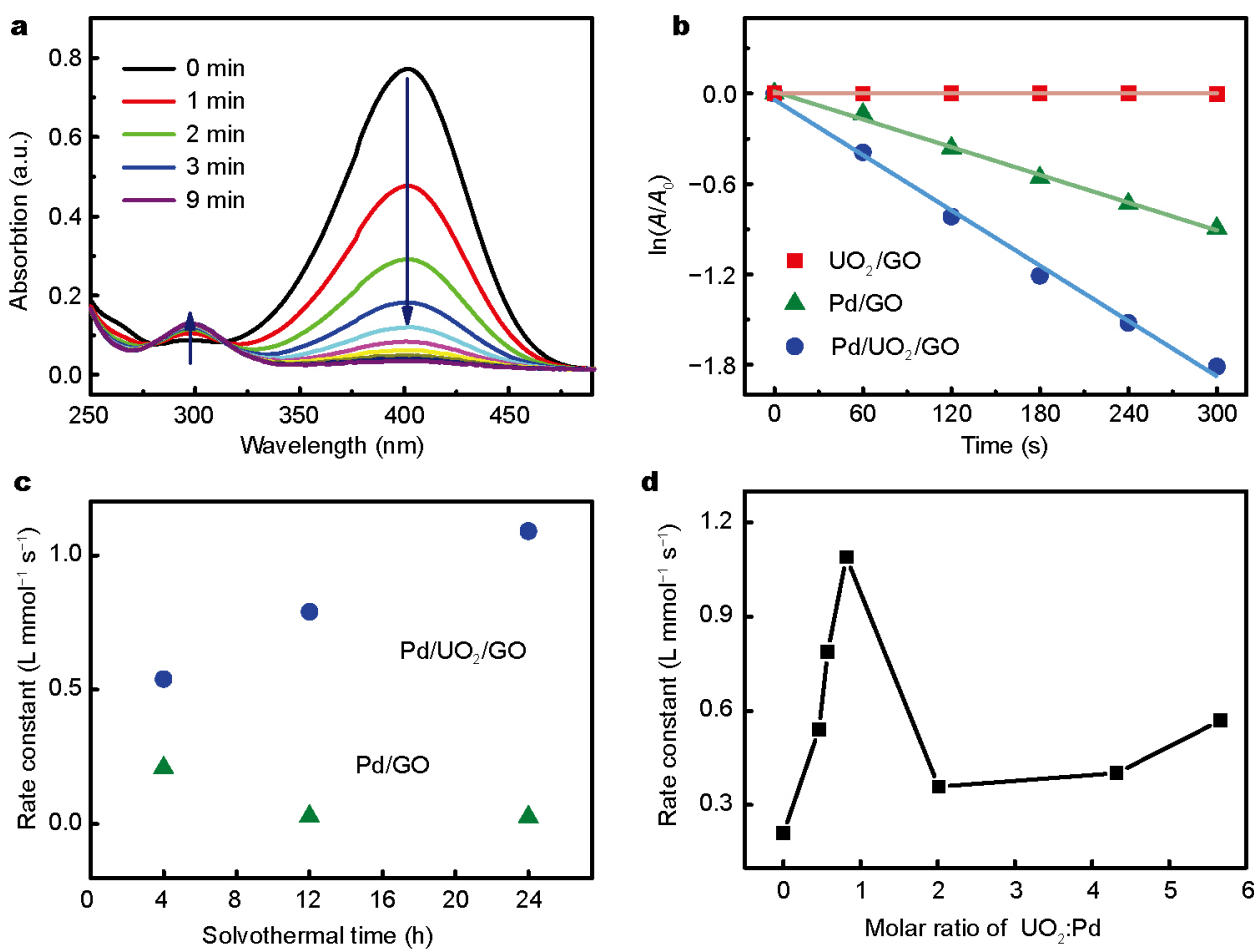

Figure 3 (a) Successive UV-vis spectra for the reduction of 4-nitrophenol catalyzed by the $\mathrm{Pd} / \mathrm{UO}_{2} / \mathrm{GO}$ hybrid with $24 \mathrm{~h}$ solvothermal treatment. (b) The kinetics study of the catalytic reaction of 4-nitrophenol over $\mathrm{UO}_{2} / \mathrm{GO}, \mathrm{Pd} / \mathrm{GO}$, and $\mathrm{Pd} / \mathrm{UO}_{2} / \mathrm{GO}$. (c) Rate constants of catalysts with different solvothermal times, and $\mathrm{Pd} / \mathrm{UO}_{2} / \mathrm{GO}, \mathrm{Pd} / \mathrm{GO}$. (d) Rate constants of catalysts with different $\mathrm{UO}_{2}: \mathrm{Pd}$ ratio. 

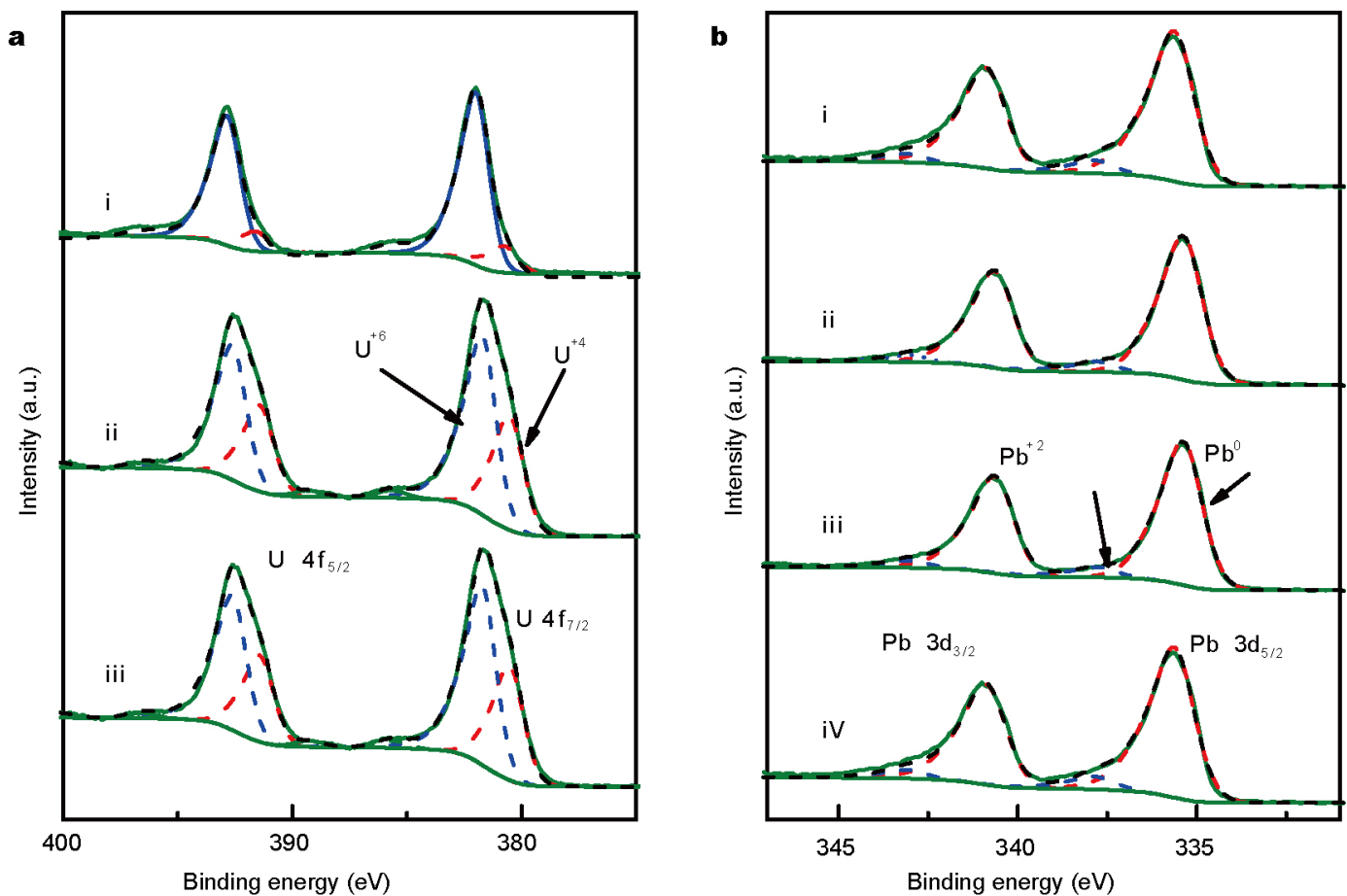

Figure 4 (a) XPS spectra of the $\mathrm{Pd} / \mathrm{UO}_{2} / \mathrm{GO}$ hybrids with different solvothermal times (i, $4 \mathrm{~h} ; \mathrm{ii}, 12 \mathrm{~h}$; iii, $24 \mathrm{~h}$ ). The spectra were fitted with peaks of $\mathrm{U}(+4)$ and $\mathrm{U}(+6)$ (dash line). (b) XPS spectra of the $\mathrm{Pd} / \mathrm{UO}_{2} / \mathrm{GO}$ hybrids with different solvothermal times (i, $4 \mathrm{~h}$; ii, $12 \mathrm{~h}$; iii, $24 \mathrm{~h}$ ), and the Pd/GO hybrid (iv) with a solvothermal time of $4 \mathrm{~h}$. The spectra were fitted with peaks of $\operatorname{Pd}(0)$ and $\operatorname{Pd}(+2)$ (dash line).

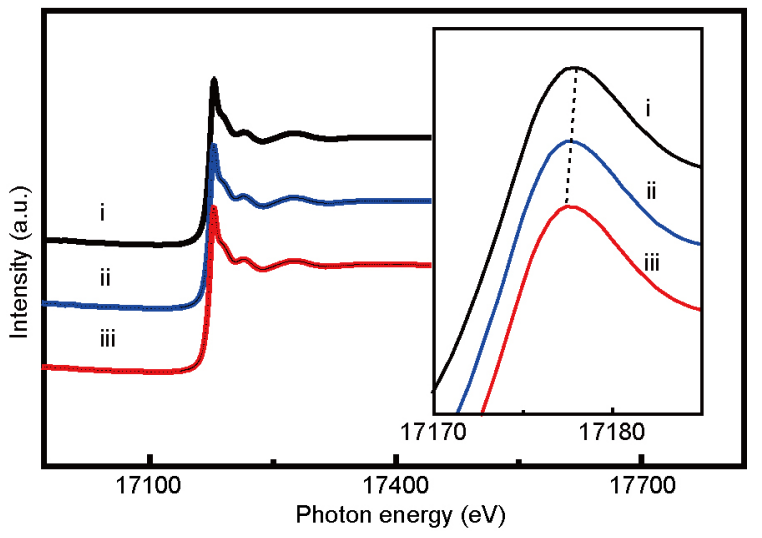

Figure 5 XAFS of U L3-edge of the $\mathrm{Pd} / \mathrm{UO}_{2} / \mathrm{GO}$ hybrids with different solvothermal times (i, $4 \mathrm{~h}$; ii, $12 \mathrm{~h}$; iii, $24 \mathrm{~h}$ ).

This phenomenon was also demonstrated by XAFS spectra in Fig. 5. The near edge absorption peak of the $\mathrm{Pd} / \mathrm{UO}_{2} / \mathrm{GO}$ with $24 \mathrm{~h}$ solvothermal treatment is $0.3 \mathrm{eV}$ lower than that of the sample with $4 \mathrm{~h}$ solvothermal treatment, which indicates the lower oxidation state of the uranium in the samples with longer solvothermal treatment. During the solvothermal process, the $\mathrm{U}(+6)$ was gradually reduced by EG. Longer solvothermal treatment should be propitious to a thorough reduction of $\mathrm{U}(+6)$. However, this might not be the only reason why uranium shows lower oxidation state with longer solvothermal treatment. As we discussed previously, $\mathrm{UO}_{2}$ crystallized better when prolonging the solvothermal time, which generally should show greater resistance to oxidation when exposed to air $[38,39]$. This effect should also be taken into account.

It is known that the reduction of 4-nitrophenol with $\mathrm{NaBH}_{4}$ follows the model of Langmuir Hinshelwood, that is, both reactants are adsorbed onto the surface to react $[29,30]$. Conventionally, Pd is regarded as the catalytic site to react with $\mathrm{BH}_{4}^{-}$by accepting electrons which transfer to 4-nitrophenol subsequently. In our catalysts, an electron transfer from palladium to uranium may take place since that $\mathrm{Pd}(5.12 \mathrm{eV})$ has a lower work function than $\mathrm{UO}_{2}(6.68$ $\mathrm{eV})[40,41]$. It is known that Fermi level alignment occurs whenever a metal and a semiconductor are placed in contact, resulting in charge redistribution and formation of a depletion layer surrounding the metal [42]. Therefore, electrons are partially transferred from Pd through a depleted region near the $\mathrm{Pd} / \mathrm{UO}_{2}$ interface to $\mathrm{UO}_{2}$, forming an electron-rich region, which was suggested by the XAFS spectra of Pd shown in Fig. 6. The Pd near edge absorption 

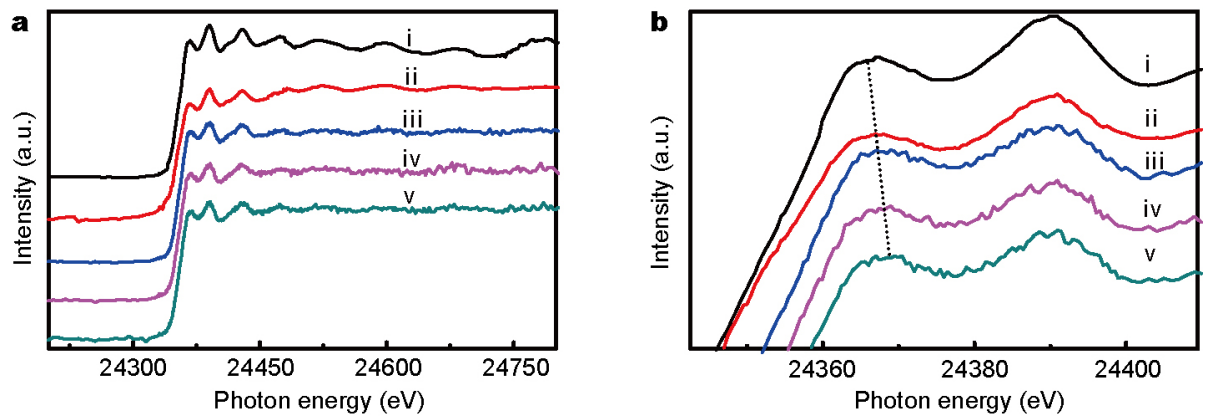

Figure 6 XAFS of the Pd K-edge of Pd foil (i), Pd/GO (ii) and Pd/UO $/$ GO hybrids with different solvothermal times (iii,4h; iv, 12 h; v, 24 h).

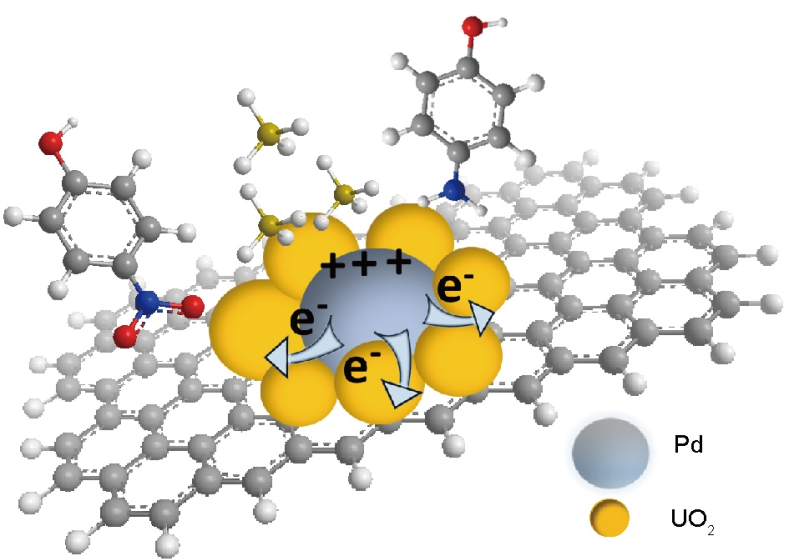

Scheme 2 The proposed mechanism of the catalytic reduction of 4-nitrophenol with $\mathrm{Pd} / \mathrm{UO}_{2} / \mathrm{GO}$ hybrids.

peak of the $\mathrm{Pd} / \mathrm{UO}_{2} / \mathrm{GO}$ with $24 \mathrm{~h}$ solvothermal treatment is $1.1 \mathrm{eV}$ higher than that of the sample with Pd/GO, indicating a slightly higher oxidation state of the Pd in the ternary hybrids. The shift of edge energy is tiny, so it might not be easily observed in the XPS profiles. Previous studies have shown that nitro groups can be easily adsorbed on the basic or reducible supports [43-45]. Hence, $\mathrm{UO}_{2}$ tends to adsorb 4-nitrophenol, which then can be further reduced by the injected electrons on $\mathrm{UO}_{2}$. Thus, $\mathrm{UO}_{2}$ may contribute to the improvement of catalytic performance by offering more active sites for both adsorption and reaction of 4-nitrophenol. That may be one of the main reasons why our $\mathrm{Pd} / \mathrm{UO}_{2}$ catalyst exhibits enhanced catalytic activity toward the reduction of 4-nitrophenol as shown in Scheme 2.

\section{CONCLUSIONS}

In conclusion, we synthesized the $\mathrm{Pd} / \mathrm{UO}_{2} / \mathrm{GO}$ nanohybrids via a solvothermal process. The Pd nanoparticles ( $\sim 4$ $\mathrm{nm}$ ) were loaded uniformly on GO and closely surrounded by nano-structured $\mathrm{UO}_{2}$ with good crystallinity, which protected $\mathrm{Pd}$ from aggregation. A charge redistribution at the $\mathrm{Pd}-\mathrm{UO}_{2}$ interface may take place and consequently $\mathrm{UO}_{2}$ can act as the promoter by offering additional active sites for both adsorption and reduction of the reactant 4-nitrophenol. Therefore, the ternary hybrids present enhanced catalytic performance toward the reduction of 4-nitrophenol to 4-aminophenol.

Received 28 February 2017; accepted 16 April 2017; published online 28 April 2017

1 Nier AO. The isotopic constitution of uranium and the half-lives of the uranium isotopes. I. Phys Rev, 1939, 55: 150-153

2 Audi G, Bersillon O, Blachot J, et al. The Nubase evaluation of nuclear and decay properties. Nucl Phys A, 2003, 729: 3-128

3 Taylor SH. Heterogeneous catalysis by uranium oxides. Jackson SD, Hargreaves JSJ (eds.). Metal Oxide Catalysis. Weinheim: WileyVCH Verlag GmbH \& Co. KGaA. 2009, 539-560

4 Idriss $H$. Surface reactions of uranium oxide powder, thin films and single crystals. Surface Sci Rep, 2010, 65: 67-109

5 Ismagilov ZR, Kuntsevich SV, Shikina NV, et al. Characterization of alumina-supported uranium oxide catalysts in methane oxidation. Catal Today, 2010, 157: 217-222

6 Gao D, Zhang Z, Ding L, et al. Preparation and electrocatalytic properties of triuranium octoxide supported on reduced graphene oxide. Nano Res, 2015, 8: 546-553

7 Pollington SD, Lee AF, Overton TL, et al. Novel supported uranium oxide catalysts for $\mathrm{NO}_{x}$ abatement. Chem Commun, 1999, 725-726

8 Hutchings GJ, Heneghan CS, Hudson ID, et al. Uranium-oxidebased catalysts for the destruction of volatile chloro-organic compounds. Nature, 1996, 384: 341-343

9 Taylor SH, O'Leary SR. A study of uranium oxide based catalysts for the oxidative destruction of short chain alkanes. Appl Catal B-Environ, 2000, 25: 137-149

$10 \mathrm{Hu} \mathrm{S}$, Li H, Liu H, et al. Nanocrystals of uranium oxide: controlled synthesis and enhanced electrochemical performance of hydrogen evolution by Ce doping. Small, 2015, 11: 2624-2630

11 Dong YY, Liao WP, Suo ZH. Uranium oxide-supported gold catalyst for water-gas shift reaction. Fuel Processing Tech, 2015, 137: 164-169

12 Choudhary VR, Jha R, Jana P. Solvent-free selective oxidation of benzyl alcohol by molecular oxygen over uranium oxide supported nano-gold catalyst for the production of chlorine-free benzaldehyde. Green Chem, 2007, 9: 267

13 Zhao Y, Tang R, Huang R. Palladium supported on graphitic carbon nitride: an efficient and recyclable heterogeneous catalyst for reduction of nitroarenes and suzuki coupling reaction. Catal Lett, 
2015, 145: 1961-1971

14 Miyaura N, Suzuki A. Palladium-catalyzed cross-coupling reactions of organoboron compounds. Chem Rev, 1995, 95: 2457-2483

15 Yu JW, Zhu W, Zhang YW. Solution synthesis protocols for shaping mixed valent oxide crystalline particles as robust catalytic materials. Inorg Chem Front, 2016, 3: 9-25

16 Li XH, Baar M, Blechert S, et al. Facilitating room-temperature Suzuki coupling reaction with light: Mott-Schottky photocatalyst for C-C-coupling. Sci Rep, 2013, 3: 1743

17 Oh SH, Hoflund GB. Chemical state study of palladium powder and ceria-supported palladium during low-temperature $\mathrm{CO}$ oxidation. J Phys Chem A, 2006, 110: 7609-7613

18 Boronin AI, Slavinskaya EM, Danilova IG, et al. Investigation of palladium interaction with cerium oxide and its state in catalysts for low-temperature CO oxidation. Catal Today, 2009, 144: 201-211

19 Li Y, Yu Y, Wang JG, et al. CO oxidation over graphene supported palladium catalyst. Appl Catal B-Environ, 2012, 125: 189-196

20 Xue Y, Lu X, Bian X, et al. Facile synthesis of highly dispersed palladium/polypyrrole nanocapsules for catalytic reduction of p-nitrophenol. J Colloid Interface Sci, 2012, 379: 89-93

21 Shan S, Petkov V, Yang L, et al. Atomic-structural synergy for catalytic CO oxidation over palladium-nickel nanoalloys. J Am Chem Soc, 2014, 136: 7140-7151

22 Souza FD, Fiedler H, Nome F. Zwitterionic surfactant stabilized palladium nanoparticles as catalysts in aromatic nitro compound reductions. J Brazilian Chem Soc, 2015

23 Noh J, Meijboom R. (2014) Reduction of 4-nitrophenol as a model reaction for nanocatalysis. Mishra AK (eds.). Application of Nanotechnology in Water Research. Hoboken: John Wiley \& Sons. 2014, 333-405

24 Julkapli NM, Bagheri S. Graphene supported heterogeneous catalysts: an overview. Int J Hydrogen Energ, 2015, 40: 948-979

25 Wu ZS, Zhou G, Yin LC, et al. Graphene/metal oxide composite electrode materials for energy storage. Nano Energ, 2012, 1: 107-131

26 Huang X, Qi X, Boey F, et al. Graphene-based composites. Chem Soc Rev, 2012, 41: 666-686

27 Machado BF, Serp P. Graphene-based materials for catalysis. Catal Sci Technol, 2012, 2: 54-75

28 Marcano DC, Kosynkin DV, Berlin JM, et al. Improved synthesis of graphene oxide. ACS Nano, 2010, 4: 4806-4814

29 He W, Jiang $\mathrm{H}$, Zhou $\mathrm{Y}$, et al. An efficient reduction route for the production of $\mathrm{Pd}-\mathrm{Pt}$ nanoparticles anchored on graphene nanosheets for use as durable oxygen reduction electrocatalysts. Carbon, 2012, 50: 265-274

30 Patterson AL. The scherrer formula for X-ray particle size determination. Phys Rev, 1939, 56: 978-982

$31 \mathrm{Gu}$ S, Wunder S, Lu Y, et al. Kinetic analysis of the catalytic reduction of 4-nitrophenol by metallic nanoparticles. J Phys Chem C, 2014, 118: 18618-18625

32 Li M, Chen G. Revisiting catalytic model reaction p-nitrophenol/ $\mathrm{NaBH}_{4}$ using metallic nanoparticles coated on polymeric spheres. Nanoscale, 2013, 5: 11919-11927

33 Wunder S, Polzer F, Lu Y, et al. Kinetic analysis of catalytic reduction of 4-nitrophenol by metallic nanoparticles immobilized in spherical polyelectrolyte brushes. J Phys Chem C, 2010, 114: 8814-8820

34 Isaifan RJ, Ntais S, Baranova EA. Particle size effect on catalytic activity of carbon-supported Pt nanoparticles for complete ethylene oxidation. Appl Catal A-General, 2013, 464-465: 87-94

35 Panigrahi S, Basu S, Praharaj S, et al. Synthesis and size-selective catalysis by supported gold nanoparticles: study on heterogeneous and homogeneous catalytic process. J Phys Chem C, 2007, 111: 4596-4605

36 Haruta M. Size- and support-dependency in the catalysis of gold. Catal Today, 1997, 36: 153-166

37 Thiele EW. Relation between catalytic activity and size of particle. Ind Eng Chem, 1939, 31: 916-920

38 Opel K, Weiß S, Hübener S, et al. Study of the solubility of amorphous and crystalline uranium dioxide by combined spectroscopic methods. Radiochim Acta, 2007, 95

39 Tobias G, Shao L, Salzmann CG, et al. Purification and opening of carbon nanotubes using steam. J Phys Chem B, 2006, 110: 22318-22322

40 Michaelson HB. The work function of the elements and its periodicity. J Appl Phys, 1977, 48: 4729-4733

41 Young C, Petrosky J, Mann JM, et al. The work function of hydrothermally synthesized $\mathrm{UO}_{2}$ and the implications for semiconductor device fabrication. Phys Status Solidi RRL, 2016, 10: 687-690

42 Bardeen J. Surface states and rectification at metal semi-conductor contact. Phys Rev, 1947, 71: 717-727

43 Boronat $\mathrm{M}$, Concepción P, Corma A, et al. A molecular mechanism for the chemoselective hydrogenation of substituted nitroaromatics with nanoparticles of gold on $\mathrm{TiO}_{2}$ catalysts: a cooperative effect between gold and the support. J Am Chem Soc, 2007, 129: 16230-16237

44 Corma A, Serna P, García H. Gold catalysts open a new general chemoselective route to synthesize oximes by hydrogenation of $\alpha, \beta$ unsaturated nitrocompounds with $\mathrm{H}_{2}$. J Am Chem Soc, 2007, 129: 6358-6359

45 Zhang S, Chang CR, Huang ZQ, et al. High catalytic activity and chemoselectivity of sub-nanometric Pd clusters on porous nanorods of $\mathrm{CeO}_{2}$ for hydrogenation of nitroarenes. J Am Chem Soc, 2016, 138: 2629-2637

Acknowledgments This work was supported by the Ministry of Science and Technology of China (2016YFA0201904), National Natural Science Foundation of China (21631002 and U1632119). The authors thank Shanghai Synchrotron Radiation Facility for providing the beam time at BL14W1.

Author contributions Ding L designed and engineered the samples; Zhang $\mathrm{Z}$ performed the experiment of EXAFS. Ding L wrote the paper with support from Zhang Z. All authors contributed to the general discussion.

Conflict of interest The authors declare that they have no conflict of interest. 


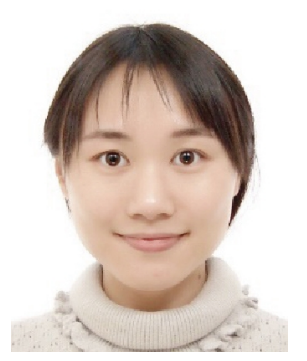

Li Ding is currently a PhD candidate in the College of Chemistry and Molecular Engineering, Peking University. She was born in Longyan, Fujian province, China in 1990. She received her Bachelor's degree from Xiamen University in 2013. Her research interests are focused on the preparation, characterization and application of uranium based materials.

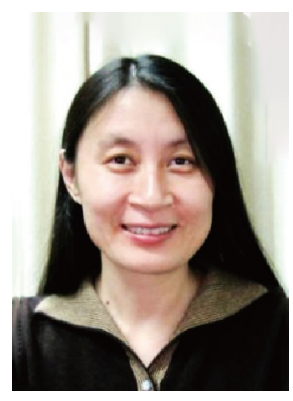

Yan Li is currently a professor in the College of Chemistry and Molecular Engineering, Peking University. She graduated in 1987 from Shandong University with a BSc degree in chemistry and received her PhD degree in inorganic chemistry from Peking University in 1993. After two years' postdoctoral research in chemistry and applied physics, she joined the Faculty of Peking University in 1995 and was promoted to a full professor in 2002. From Nov. 1999 to May 2001, she was a visiting associate professor in Duke University, USA. She also holds a distinguished visiting professor position in the University of Tokyo. Her research focuses on the preparation, characterization, properties, and applications of functional nanomaterials and nanostructures, especially carbon nanomaterials.

\section{二氧化铀-钯-石墨烯纳米复合材料的合成及其催化4-硝基苯酚还原反应的研究}

丁莉, 张则尧, 李彦 ${ }^{*}$

摘要 本文通过溶剂热方法合成了二氧化铀-钯-石墨烯纳米复合材料. 在这种复合材料中, 金属钯和二氧化铀的纳米晶负载在石墨烯氧 化物上, 且钯纳米晶与二氧化铀纳米晶密切接触. 这一复合材料对4-硝基苯酚还原反应表现出良好的催化活性, 二氧化铀在其中发挥了关 键作用. 二氧化铀有效地防止钯颗粒在溶剂热过程中团聚、长大; 此外, 在钯与二氧化铀界面处, 电子从钯转移至二氧化铀表面, 为催化还 原反应提供了更多的吸附和反应位点, 从而有效地提高了催化剂活性. 